\section{Kounis Syndrome After Intake of Levofloxacin: Increasing Incidence of Hypersensitivity to Fluoroquinolones}

Kounis NG, Koniari I, Soufras G

Department of Cardiology, University of Patras Medical School, Rion, Patras, Achaia, Greece

J Investig Allergol Clin Immunol 2017; Vol. 27(1): 76-77 doi: $10.18176 /$ jiaci.0124

Key words: Anaphylaxis. Kounis syndrome. Levofloxacin. Quinolones.

Palabras clave: Anafilaxia. Síndrome de Kounis. Levofloxacino. Quinolonas.

\section{To the Editor:}

We read with great interest the report published in the Journal of Investigational Allergology and Clinical Immunology [1] of a case of generalized angioedema with urticaria and immediate reaction after intake of levofloxacin by a 35-year-old man with sinusitis who had experienced an episode of type I variant of Kounis syndrome. While the results of the prick and intradermal tests were negative, the basophil activation test yielded a positive result for levofloxacin (4.5\%), as did the specific IgE determination. We believe that the following comments concerning this report might be of value.

1. This patient was young and had sinusitis. Acute bacterial rhinosinusitis can be complicated by development of allergic fungal rhinosinusitis, which is the most common form of fungal sinusitis in the United States [2]. This condition is associated with a predisposed person's type I IgE-mediated allergic response to inhaled mold spores that are ubiquitous in the environment. Indeed, common allergic symptoms were found to be significantly associated with an increased risk of coronary heart disease and Kounis syndrome [3].

2. The patient developed Kounis syndrome with the first dose of levofloxacin. Clinical studies indicate that susceptible individuals simultaneously exposed to multiple allergens more frequently have symptoms than monosensitized individuals [4]. Furthermore, $\mathrm{IgE}$ antibodies with different specificities can have additive effects, and small, even subthreshold numbers, can join forces and trigger mast cells to release their mediators [5].

3. Given that fluoroquinolones are well-tolerated and therefore increasingly consumed, the frequency of allergic reactions has risen. Consequently, fluoroquinolones are now the drugs most frequently involved in allergic drug reactions after $\beta$-lactams [6]. IgE-mediated anaphylaxis and urticaria are the most frequent manifestations [7]. Kounis syndrome has been induced not only by ciprofloxacin and levofloxacin, but also by the original quinolone cinoxacin [8]. More cases are expected to be reported in the future. Therefore, it seems wise to maintain a high index of suspicion.

4. We agree with the authors of the report [1] that no diagnostic and therapeutic criteria of Kounis syndrome have been established to date. However, a large group of expert immunologists, allergists, cardiologists, anesthetists, and surgeons has agreed to convene in order to establish these criteria. We urge any scientist with interest and experience in this syndrome to participate.

\section{Funding}

The authors declare that no funding was received for the present study.

\section{Conflicts of Interest}

The authors declare that they have no conflicts of interest.

\section{References}

1. García Núñez I, Algaba Mármol MA, Barasona Villarejo MJ, Suárez Vergara M, Espínola González F, Reina Ariza E. Kounis Syndrome After Levofloxacin Intake: A Clinical Report and Cross-reactivity Study. J Investig Allergol Clin Immunol. 2016;26:335-6.

2. Carr TF. Complications of sinusitis. Am J Rhinol Allergy. 2016;30:241-5

3. Kim J, Purushottam B, Chae YK, Chebrolu L, Amanullah A. Relation between common allergic symptoms and coronary heart disease among NHANES III participants. Am J Cardiol. 2010;106:984-7.

4. Nopp A, Johansson SG, Lundberg M, Oman H. Simultaneous exposure of several allergens has an additive effect on multisensitized basophils. Allergy. 2006;61:1366-8.

5. MacGlashan DW Jr, Brochner BS, Adelman DC, Jardieu PM, Togias A, Mckenzie-White J, Sterbinsky SA, Hamilton RG, Lichtenstein LM. Down-regulation of FceRI expression in human basophils during in vivo treatment of atopic patients with anti-lgE antibody. J Immunol. 1997;158:1438-45.

6. Dona I, Blanca-Lopez N, Torres MJ, García-Campos J, GarcíaNúñez I, Gómez F, Salas M, Rondón C, Canto MG, Blanca M. Drug hypersensitivity reactions: response patterns, drug involved, and temporal variations in a large series of patients. J Investig Allergol Clin Immunol. 2012;22:363-71. 
7. Fernández TD, Ariza $A$, Palomares $F$, Montañez MI, Salas $M$, Martín-Serrano A, Fernández R, Ruiz A, Blanca M, Mayorga C, Torres MJ. Hypersensitivity to fluoroquinolones: The expression of basophil activation markers depends on the clinical entity and the culprit fluoroquinolone. Medicine (Baltimore). 2016;95:e3679.

8. Quercia O, Rafanelli S, Emiliani F, Stefanini GF. Anaphylactic reaction to cinoxacin: report of one case associated with inferior acute myocardial infarction. Eur Ann Allergy Clin Immunol. 2003;35:61-3.
Manuscript received November 5, 2016; accepted for publication November 25, 2016.

\section{NG Kounis}

Queen Olgas Square, 7 Aratou Street

Patras 26221, Greece

E-mail: ngkounis@otenet.gr 